\title{
The Metaphysical Turn in Environmental Philosophy
}

\author{
Lawrence W. Howe \\ University of West Florida
}

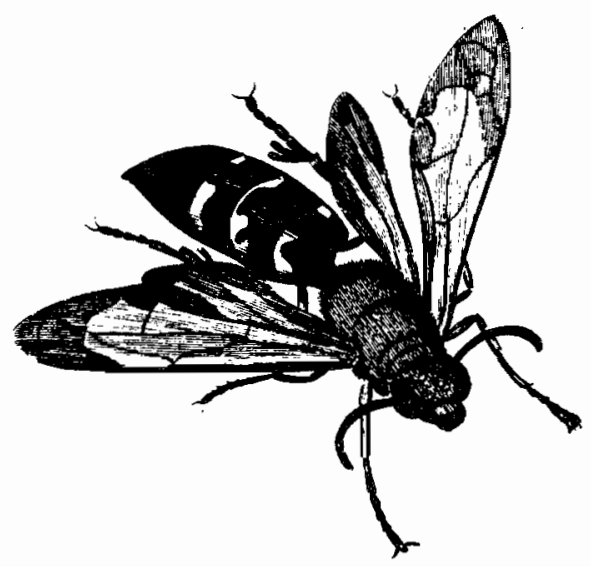

The history of environmental ethics reveals that ecophilosophers have demonstrated an intense interest in metaphysical issues. The purpose of this paper is to discuss the problems that have driven the development of metaphysical themes and the bearing they have had upon ethical issues in the field of environmental philosophy. In particular I want to discuss the way that anthropocentric ethics and biocentric ethics have interacted with metaphysical approaches. I am assuming that metaphysical issues have been raised in the effort to determine ethical positions in discussions concerning humanity's obligation to the environment.

According to Devall and Sessions, one of the crucial themes facing the construction of an environmental philosophy revolves around the metaphysical view of humanity's place in nature. They recommend that "an appropriate metaphysics for the emerging perennial philosophy would provide a structured account of the basic unity and interrelatedness of the universe while at the same time accounting for the importance and uniqueness of individual beings." 1 The metaphysical view articulated would be one that not only recognizes the worth of all individuals, it would also recognize that individuals are ultimately interrelated parts of

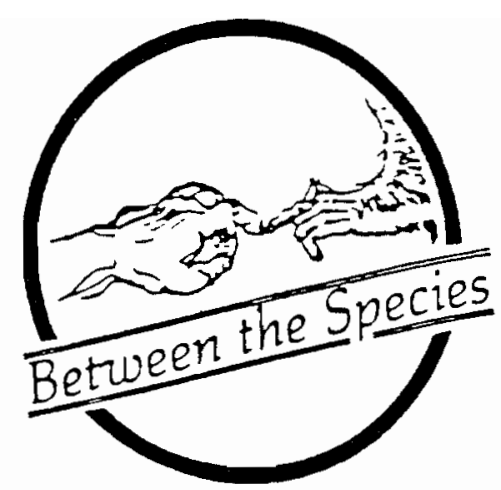

nature. For Devall and Sessions, such a metaphysics would begin to lay the ground for an environmental philosophy that is nonanthropocentric.

The nonanthropocentric view stands in contrast to the traditional anthropocentric view which holds that values are human-centered and anything that is nonhuman can only be regarded as instrumentally valuable, i.e. valuable as a means to human ends. On the other hand, a nonanthropocentric position holds that humans are part of nature and that the nonhuman community is to be regarded as intrinsically valuable.

I want to suggest that one of the crucial tasks confronting environmental philosophy today involves the development of a world-view which extends beyond considerations of ethical theory alone. Remarking on the need for a supporting metaphysics in environmental philosophy Blackstone stated: "The question that must be asked is how we must understand the world if we are to find a place in it for the inherent value of nonhuman life forms?"2 And Devall and Sessions complain that specialists in philosophy "do ethical theory entirely divorced from its metaphysical underpinnings..." and add that, "Such specialists are of little help in developing the deep ecology world-view now needed." 3

Warwick Fox avers that in the past environmental philosophy had been primarily "concerned with developing a theory of value in regard to the non-human

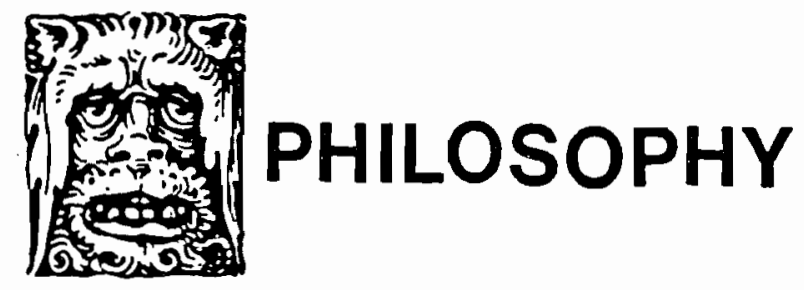


world. Such a theory is more formally referred to as an environmental axiology...."4 Thus environmental philosophy has had an axiological orientation rather than a metaphysical one; however, recent studies more and more indicate a transition from the axiological dialogue of values to the metaphysical dialogue concerned with developing a picture of the world that enriches and informs our cognitive grasp of humanity's interrelatedness with nature. ${ }^{5}$

What are the reasons for the metaphysical interest in this field? To a large degree environmental philosophy emerged against the background of anthropocentric attitudes towards nature which in turn gave rise to the debate between anthropocentric and biocentric theories of value. These two views have been opposed to one another throughout the history of environmental ethics. The biocentric ethic appears to defend a position that is unacceptable to traditional ethics which conceives of humanity as the center of value. The biocentric philosophers have endeavored to go beyond traditional positions to support their ethical views. The biocentrists have turned to metaphysics as a means for providing the required support. Therefore the metaphysical interests appear to be driven by a demand to revamp traditional anthropocentric attitudes towards nature. According to one philosopher the anthropocentric conception of the world was "typified by technology and science; with its underlying philosophy of modern day materialism, Cartesian dualism, and mechanistic naturalism, the concept of environment of modern man was very much objectified, mechanized, rigidified, dehumanized, and possibly even de-enlivened, and so de-environmentalized." 6

This reaction of the anthropocentric view suggests that the transition from the anthropocentric view to the nonanthropocentric view reflects a desire to recover humanity's interrelatedness with nature. The effort to make this recovery takes us to a metaphysical account of the most basic features of existence. While metaphysics with its partly checkered and partly hallowed history may not be capable of demonstrating the nature of the world with logical necessity, it is capable, I believe, of showing the conceptual possibilities inherent in a view that recognizes the interrelatedness of all aspects of the world while not separating man from the rest of the world. The metaphysical turn in ecology endeavors to show why one paradigm may be more desirable than another; recent studies have focussed on elaborating concepts that are required to erect a non-anthropocentric paradigm.

William Grey characterizes the position of nonanthropocentrism and its opposition to anthropocentrism in the following way:

the evils of the modern industrial state are produced by a particular set of anthropocentric attitudes and beliefs... An examination of the deep ecology of present Western society reveals a constellation of attitudes and values which we can call the 'technocratic' paradigm; it is essential that this paradigm be replaced by an alternative which will enable human societies to develop sustainable modes of living in co-operative harmony with our human and non-human companions within the complex and integrated biosphere which we share... The recognition of the need for a radically different paradigm is the distinguishing mark which separates shallow 'reformist' environmentalism from 'deep ecology'. Shallow environmentalism remains imprisoned by the dominant anthropocentric attitudes which are (or tend to be) mechanistic and reductionistic, in comparison to the holistic, biocentric, non-reductionist conceptions which are advocated by deep ecology.

Here Grey recognizes that the issue at stake is a debate over competing paradigms rather than a debate over instrumental versus intrinsic value theory. In this respect the term paradigm means an organized and structured set of beliefs that serve to prefigure significant judgments about the world. Paradigms are essential in that they serve as models for informing the way we see the world.

Andrew McLaughlin, in his paper "Images and Ethics of Nature," reinforces the idea that the crucial matter for environmental philosophy is the conceptual framework that recommends how we see the world. What is at issue, he urges, is how we regard the humanity/nature relationship. "If, instead of seeing nature as separate from humanity, we see humanity and nature as one matrix, then it is clear that we are part of nature. Our relations to nature are internal, in the sense that we are as we are because of the larger context within which we exist." 
McLaughlin's view implies a monism that is revisionistic in that it focuses on how the humanity/ nature relation ought to be conceived, although it is not reductionistic since the integrity of the parts that compose nature are preserved. Besides suggesting a revision of anthropocentric attitudes towards nature, it is also evident that McLaughlin's "image of nature" is tied to the doctrine of internal relations.

Historically that doctrine has played a prominent role in the development of monistic metaphysics in general and idealism in particular. The linkage of this doctrine with theories of reality has been made by metaphysicians such as Hegel, Bradley, Royce, McTaggart and Blandshard. These idealists insisted that interrelations are so complex that all things are connected within an organic unity; a change in any one thing would ultimately change all other things. This doctrine plays a key role in speculative metaphysics for those philosophers who conclude that the universe must be conceived as a unity.

In 1973 Arne Naess pointed out that ecology had resurrected the doctrine of internal relations. ${ }^{9}$ Agreeing with Naess, J. Baird Callicott remarked that:

\section{Whatever the motive of the idealists (coherency theories of truth, the omniscience and omnipresence of spirit or whatever) and notwithstanding the inevitable entanglement of the doctrine of internal relations with other currently fashionable topics by mid-century neo-scholastics, academic philosophers (with 'bare particulars', nominalism, the analytic- synthetic distinction and so on) internal relations are straightforwardly implicated in ecology. ${ }^{10}$}

The doctrine of internal relations could play an essential role in constructing a holistic conception of nature; however, the metaphysics that embraces this doctrine is more closely aligned today with process philosophies rather than with the "block universe" models suggested by Absolute Idealism dominant in the nineteenth century. With regard to the process view Callicott remarks that "an object ontology is inappropriate to an ecological description of the natural environment. Living natural objects should be regarded as ontologically subordinate to 'events' and/or 'flow patterns' and/or 'field patterns" "." Callicott goes on to point out that the organic conception of the world is not alien to the feature of process and internal relations. According to

the 'organic' concept of nature implied by the New Ecology as in that implied by the New Physics, energy seems to be a more fundamental and primitive reality than material objects and discrete entities-elementary particles and organisms respectively. An individual organism, like an elementary particle is, as it were, a momentary configuration, a local perturbation, in an energy flux or 'field'. ${ }^{12}$

The emphasis placed on process, internal relations and organicism is part and parcel of the attempt to establish a holistic image of nature that embraces humanity as an integral component of nature as a whole. Thus McLaughlin asks us to revise the idea of ecology when he writes that, "Ecology, understood narrowly as the study of the interrelations between nonhuman organisms and their environments, may not force a fundamental change in our image of nature. However, when this image is applied self-referentially, it does require a fundamentally new image of nature." 13 To apply the image self-referentially is to conceive of humanity as a part of the interconnected whole, not as a disinterested objective observer.

The emergent interest in metaphysics suggests that an anthropocentric ethic can be replaced through a revision of humanity's place in nature. If this trend toward revision continues, then the aim of environmental philosophy will be less concerned to develop a theory of rights and obligations and more concerned to articulate a comprehensive world-view; that is, a set of concepts-suggestive of man's interrelations with the world-that allows us to articulate and interpret our experience of the world.

The metaphysical approach in environmental philosophy has been forcefully brought out by Michael Zimmerman who argues that "to determine what kinds of behavior are morally appropriate, we must know what we ourselves and other beings are. In other words, ontology precedes ethics."14 Zimmerman's emphasis on ontology over ethics is becoming more and more a part of mainstream philosophical discussions in environmental philosophy. According to this approach one's ethical position is dependent upon and derives from one's metaphysical view. As Zimmerman remarks, 
"before knowing what we ought to do, we must understand who we really are." 15

As far as Zimmerman is concerned ethics has been, or ought to be, superseded by metaphysics-a point certainly brought out by the deep ecologists in their quest to turn to metaphysics as a source for recharging environmental philosophy and cultivating an ecological consciousness. "Academically speaking," says Naess, "what I suggest is the supremacy of environmental ontology and realism as a means of invigorating the environmental movement in the years to come."16

Agreeing with Zimmerman, Fox holds that the metaphysical turn emphasizes the experience of "commonality with all that is that is brought about through deep-seated realization of the fact that things are." 17 Here Fox reminds us of Wittgenstein's claim that "It is not how things are in the world that is mystical, but that it exists." 18 In other words, the ontologically based approach is not directed toward giving an inventory of the furniture of the world, rather it is intended to refer to the fact of existence itself. As Fox says:

that things are impresses itself upon some people in such a profound way that all that exists seems to stand out as foreground from a background of nonexistence, voidness, or emptiness-a background from which this foreground arises moment by moment. This sense of specialness or privileged nature of all that exists means that 'the environment' or 'the world at large' is experienced not as a mere backdrop against which our privileged egos and those entities with which they are most concerned play themselves out, but rather just as much an expression of the manifestation of Being (i.e. of existence per se) we ourselves are. ${ }^{19}$

Fox's ontologically based approach not only emphasizes the fact that things are, it also points out that everything is experienced as an interconnected feature of existence. Although his position draws heavily upon Eastern sources, it should be noted that in the West metaphysical theories combining the insights of modern science with concepts of process and unity also offer rich sources for environmental philosophy. In his book, The Rights of Nature, Roderick Nash refers to "the 'new' physics as interpreted by process philosopher Alfred North Whitehead," and remarks that the "heart of the theory was the idea that identity of the individual was indistinguishable from the identity of the whole, interrelated process." ${ }^{20}$ William Grey argued that Western philosophy has the conceptual resources to construct a metaphysics that recognizes man as part of nature. "The realization that we are part of the natural world," says Grey, "is an important preliminary to acting wisely within it (as has been repeatedly stressed), but there is no need to turn to exotic traditions to find a solid foundation for this important step." ${ }^{21}$ Thus Grey. would agree that appropriate ethical behavior follows as a consequence of a world-view that sees humanity as an integral part of nature. Moreover, he maintains that contemporary science and philosophy are quite capable of informing a model of the world and our place in it.

Recent work in science has made a crucial contribution to the shaping of a new paradigm for environmental philosophy. "Modern science," writes Fox, "is providing an increasingly detailed account of the physical and biological evolution of the universe that compels us to view reality as a single unfolding process."22 In our century several philosophers have utilized science in the attempt to construct world-views that sponsor process, unity, and interrelatedness. Most notably, Bergson drew upon and was influenced by biology and Whitehead constructed a metaphysical world-view on the basis of his interpretation of physics. Zimmerman has applied the work of the physical chemist Ilya Prigogine to argue that the ideas in environmental philosophy such as "internal relationships, evolution, emergent qualities, and spontaneous generation of order stand in striking contrast to the nineteenth century view of the universe as a gigantic clockwork whose character and destiny are prefigured according to strict, unchanging causal law."23

The metaphysical approach that sponsors a biocentric ethic supports an organic/holistic conception of reality in which individuals are ultimately identified with the world as a whole; the emphasis on identification stands "in contrast to the objective axiological approach that predominates in ecophilosophy generally." 24

Would such a move away from the axiological approach burden us with so much metaphysical baggage that our philosophy would be more dubious than ever? Metaphysical world-views may not admit of logical proof as conceived of in a strict rationalistic system; however it does not follow from this that they lack cognitive status. Like science, metaphysics proposes 
paradigms that are systems of coherent propositions. Such systems provide definitions and interpretation principles as criteria against which evaluations can be made. One of the problems with anthropocentrism is that it assumes, unanalyzed, a system that supports traditional ethical standards. It is essential here to point out that what is important for metaphysics is not whether its assumptions are verifiable, but that it has the potential for recommending a way of looking at the world. Metaphysics may suggest plausible accounts of the structure of reality and provide criteria for evaluating alternative world-views.

Such accounts would also utilize recent developments in science that contribute to the construction of models for conceiving of the humanity/nature relationship. With reference to the new physics arising out of modern science, Callicott observes that a "consolidated metaphysical consensus, thus, appears to be presently emerging from twentieth century science which may at last supplant the metaphysical consensus distilled from the scientific paradigm of the seventeenth century." ${ }^{25}$ And Zimmerman, in his paper, "Quantum Theory, Intrinsic Value, and Panentheism," investigates quantum theory for the purposes of arguing that nature is an internally related field of events. "The paradigm of internal relations," writes Zimmerman, "lets us view ourselves as manifestations of a complex universe; we are not apart, but are moments in the open-ended, novelty producing process of cosmic evolution." 26

I am not arguing for the bold claim that science is moving toward a holistic interpretation of reality nor do I claim to be qualified to make that evaluation; however, it should be noted that many of the ecophilosophers today will argue that modern science is certainly amenable to holistic interpretations of nature. Metaphysics and modern science may suggest rich conceptual resources for the new picture emerging out of environmental philosophy. This new picture seeks to emphasize nature as a unitary whole without drawing a rigid ontological distinction between self and world; both are conceived of as integrative unfolding processes. The metaphysical turn will require an investigation of those concepts that are best equipped for construction of the new image of nature. We can be reminded of Whitehead who thought that the task of constructing a world-view is to articulate the most general ideas in terms of which our experience of the world can be meaningfully interpreted.
What is the value of metaphysical world-views which seem far removed from the environmental crisis? A theoretical view of nature-informed by science and philosophy-will not bring about any immediate changes, but it may initiate a break with our ingrained attitudes and habits that condition our interactions with the environment. Susan Buck-Armstrong alludes to Whitehead who "likens the effect of a great idea to that of a 'phantom ocean' whose waves are 'as dreams slowly doing their work of sapping the base of some cliff of habit". "27 A new image of nature may gradually encourage us to act consistently with a view that sponsors a non-anthropocentric system of beliefs.

The reason why the metaphysical issues are relevant to the ethical debate is that the metaphysical position adopted will prefigure the ethical position that one accepts. The difference in the metaphysical assumptions we adopt is crucial since they determine what beings count morally. The system is correct which best protects and sustains life, value and value experiences. I want to argue that the biocentric ethic is plausible because it is supported by a view that conceives of humanity as an integral part of nature. As a result nature is conceived of as having intrinsic value. Biocentrism, as opposed to anthropocentrism, supports attitudes toward nature that do not lead to destruction of the natural order of man's place in it. The adoption of this position is the result of accepting the organic/holistic interpretation of reality.

The metaphysics that I argue for is straightforwardly holistic. The fashion today in environmental philosophy is to level the charge of environmental fascism against such a position. ${ }^{28}$ Essentially this is the charge that holism would justify sacrificing individuals for the good of the whole biotic community. The problem with this criticism, however, is that it fails to recognize the integrity of the individuals that the holistic system supports. To have regard for the interests of the whole is, in effect, to guarantee that the individuals integrated within the whole must be permitted, for the health of the system, to realize their functions. Once this feature of holism is acknowledged the charge of environmental fascism loses its bite.

I have maintained throughout this paper that some recent work in environmental philosophy illustrates a trend to develop a biocentric ethic that is supported by a holistic world-view. I have not attempted to elaborate on the metaphysical systems that have been applied to environmental philosophy for the purposes of grounding 
an environmental ethic nor have I attempted to add another metaphysics to the discussion. I have tried to underscore a transition in the way some thinkers are beginning to approach problems in environmental philosophy. The metaphysical views espoused by these thinkers are only in a nascent stage; still required is the unification, clarification and refinement of key terms such as process, events, organic unity and internal relations if a new paradigm for environmental philosophy is to be erected.

\section{Notes}

1 B. Devall and G. Sessions, Deep Ecology (Peregrine Smith Books, 1985), pp. 81-82.

${ }^{2}$ W. Blackstone, "The Search for an Environmental Ethic" in Matters of Life and Death, ed. T. Regan, p. 311.

${ }^{3}$ Deep Ecology, p. 81.

${ }^{4}$ W. Fox, Toward A Transpersonal Ecology (Shambhala Press, 1990), p. 149.

${ }^{5}$ See Nash's account of this movement in his chapter "The Greening of Philosophy" in The Rights of Nature (Wisconsin Press, 1989).

${ }^{6} \mathrm{C}$. Cheng, "On the Environmental Ethics of the Tao and the Ch'i," p. 353, Environmental Ethics, 1986.

${ }^{7}$ W. Grey, "A Critique of Deep Ecology," p. 211, Journal of Applied Philosophy, 1986.

${ }^{8}$ A. McLaughlin, "Images and Ethics of Nature," pp. 312313, Envinonmental Ethics, 1985.

${ }^{9}$ A. Naess, "The Shallow and Deep Long-Range Ecology Movement. A Summary.” Enquiry 16, 1973.

$10 \mathrm{~J}$. Callicott, "The Metaphysical Implications of Ecology," p. 311, Envimonmental Ethics, 1986.

${ }^{11}$ Ibid., p. 309.

12 Ibid., p. 310.

${ }^{13}$ McL_aughlin, "Images," p. 312.

${ }^{14}$ M. Zimmerman, "Implications of Heidegger's Thought for Deep Ecology,” pp. 22-23, The Trumpeter, 1986.

15 Ibid., p. 23.

${ }^{16}$ A. Naess, "Self-Realization: An Ecological Approach," p. 36, The Trumpeter, 1987.

${ }^{17}$ W. Fox, Toward A Transpersonal Ecology, p. 250.
${ }^{18}$ Ibid.

${ }^{19}$ Ibid., p. 251.

${ }^{20}$ Nash, The Rights of Nature, p. 151.

${ }^{21}$ W. Grey, "A Critique," p. 215.

${ }^{22}$ Fox, Toward A Transpersonal Ecology, p. 251.

${ }^{23}$ Zimmerman, "Implications," p. 17.

${ }^{24}$ Fox, Toward A Transpersonal Ecology, p. 226.

${ }^{25}$ Callicott, “Metaphysical Implications,” p. 302.

${ }^{26}$ M. Zimmerman, "Quantum Theory, Intrinsic Value, and Panentheism," p. 17, Environmental Ethics, 1987.

${ }^{27}$ S. Buck-Armstrong, "Whitehead's Metaphysical System as a Foundation for Environmental Ethics," p. 251, Environmental Ethics, 1986.

${ }^{28}$ T. Regan, "Ethical Vegetarianism and Commercial Animal Farming," in Contemporany Moral Problems, ed. J. White (St. Paul, Minn.: West Publishing Co. 1985), pp. 279-94.

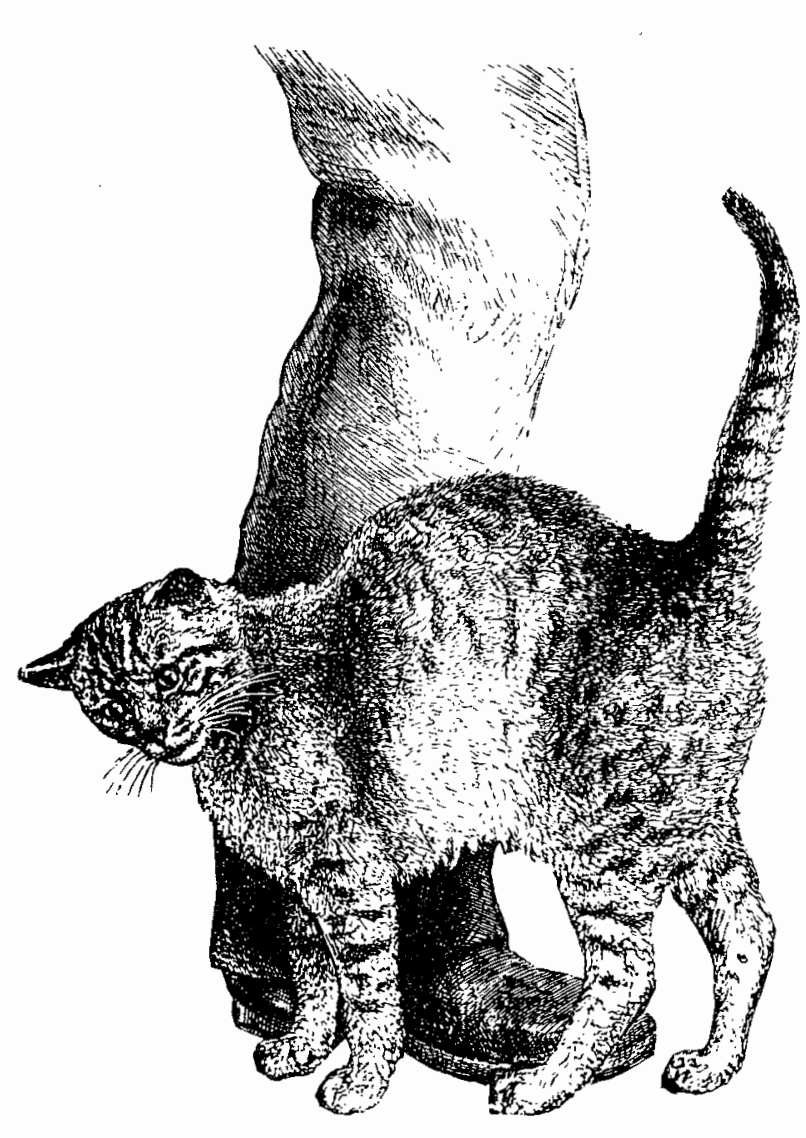




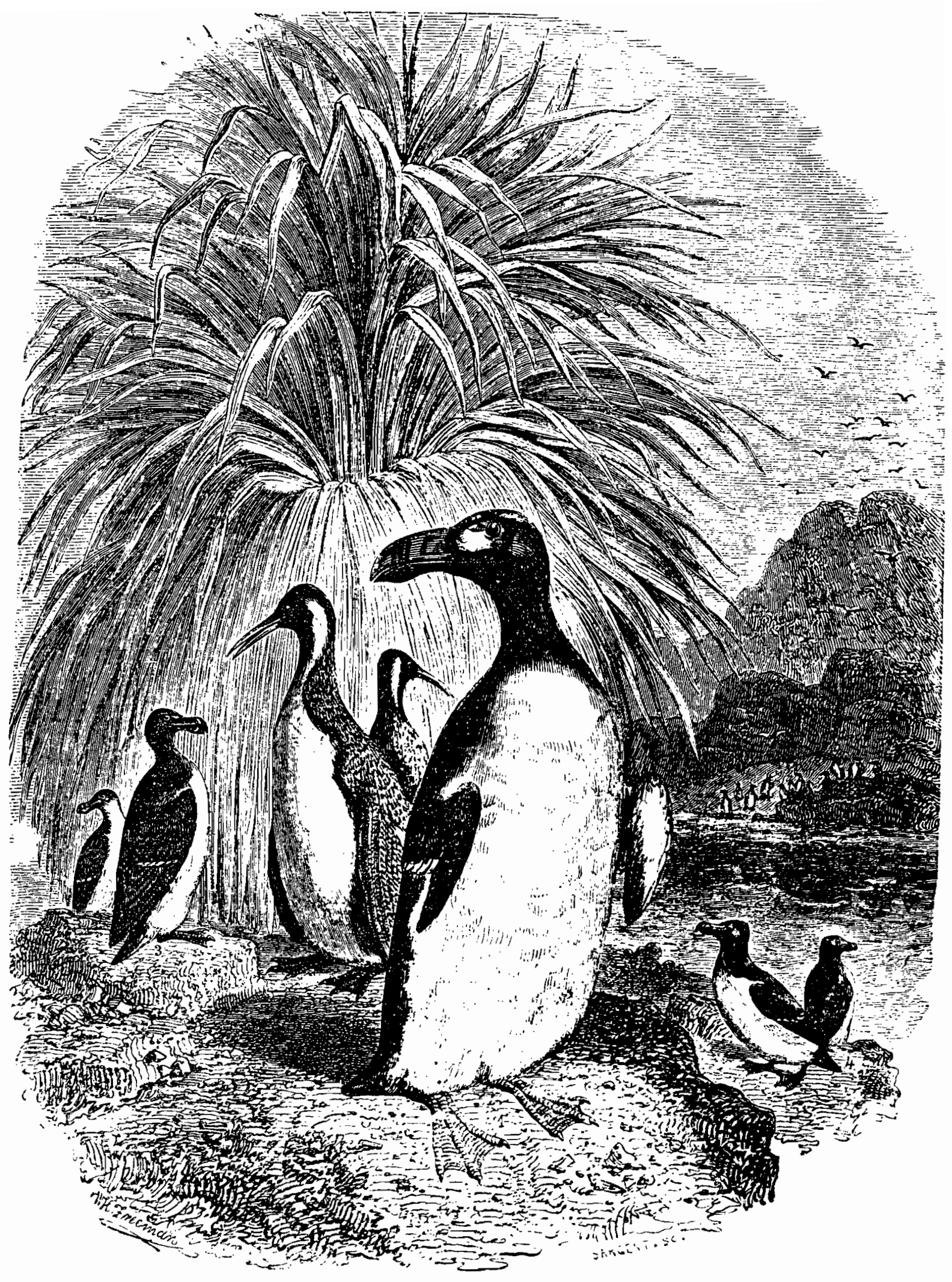

